\title{
Assessment of level of Knowledge and Practice of Patients Undergoing Cardiac Catheterization
}

\section{Hanaa Elsayed Amin'1, Ph.D Ola Abd El Aty Ahmed ${ }^{2}$, Ph.D Naglaa Elsayed Mahedy ${ }^{3}$, Ph.D Mona Hassan Ibraheem ${ }^{4}$; Ahmed Tageldin Abdellah 5}

\author{
Medical Surgical Nursing ${ }^{1,2,3,4}$, cardiovascular $^{5}$ Department, Faculties of Nursing 1, 2, 3,4
} and Medicine ${ }^{5}$, Suez Canal ${ }^{1,4,5}$ and Ain Shams ${ }^{2,3}$ Universities

\begin{abstract}
Background:Cardiac catheterization is the gold standard diagnostic test for Coronary artery diseases. Coronary artery diseases are the most common type of heart disease. Patients undergoing Cardiac catheterization, can be extremely intimidating, adequate knowledge and practice about the procedure is critical. Benefit of knowledge and practice acquisition, enhanced self-care, reduced anxiety, increased satisfaction with care and improved pain. Aim of the study: The aim of the present study was to determine the level of Knowledge and Practice of Patients Undergoing Cardiac Catheterization. Research Design: A descriptive design was used in this study. And it was conducted at the Cardiac Catheterization Unit, affiliated to Suez Canal University Hospitals in Ismailia. A convenient sample of 100 patients undergoing cardiac catheterization, were assigned. Two tools were used. Tool one: Patients' Interview questionnaire was used to assess patients' knowledge designed by the researcher based on relevant literature review. Tool two: Patient's observational checklists were used to assess patients' practice adapted by the researchers based on relevant literature review. Results: The majority of study population had unsatisfactory level of knowledge and practice with high statistically significance difference as $\mathrm{p}$ value $<0.001$. Conclusion: Most of study population had unsatisfactory level of knowledge and practice. Recommendation: Application of educational guidelines into training for patients undergoing cardiac catheterization to support knowledge and practice and increase perception and intellectual patients' skills, Educational guidelines on knowledge and practice for other cardiac devices and application of the present study with larger subjects at different places in Egypt to generalize the results.
\end{abstract}

Key Words: Cardiac catheterization, knowledge and practice 


\section{INTRODUCTION}

Cardiac catheterization (CC) is the gold standard diagnostic test for coronary heart diseases (Mauro, etal 2014). Cardiac catheterization has evolved over the last six decades to a highly specialized discipline for diagnostic purposes and an expanding repertoire of therapeutic advances to treat many problems (Rashad, 2011; Robert, 2012; Mukherjee, etal 2017). Femoral arterial puncture is the standard technique used to access the coronary arteries during coronary angiography, electrophysiological studies and diagnostic catheterization of the aorta, renal, mesenteric, carotid and upper extremity arteries. (Mohammed, 2014 and Amin, 2015).

Coronary artery disease (CAD) is the most common type of heart disease and constitutes the most important health problem affecting people of productive age (Tillmann, etal 2018). In 2006, more than 1,115,000 angiograms were performed in the USA to diagnose and treat patients with vascular diseases (Mohammady, etal, 2013 \& Mauro,_2014). Worldwide in 2007, one-quarter of all deaths $(616,000)$ were from diseases of the heart (Amin, 2015). In 2008, 405,309 people died from coronary heart disease. In USA approximately every 25 seconds, an American will have a coronary event, and approximately every minute, someone will die of CAD (Minino, etal 2012).

In the developing world, CA diseases tend to affect people at a younger age and thus could negatively affect the workforce and economic productivity (Wells \& Möller, 2015). In Egypt, according to the latest WHO data published in April 2011 coronary heart disease deaths in Egypt reached 78,897 (21.73\%) of total deaths. The age adjusted Death Rate is 173.98 per 100,000 of population ranks Egypt 33 in the world. (Amin, 2015).

Educational guidelines relevant to the patient's level of understanding, comprehensive, delivered at the appropriate time, as well as designed to understand can be one of the prerequisites for the patient to increase knowledge, practice, motivation and awareness of the importance of co-responsibility to make decisions about medical treatment and improving the patient's outcomes (Bēta, 2014 ; Koren \& Sharaf, 2016). Longer education plays a causal role in lowering the risk of coronary heart disease.In conjunction with the results from other study designs, increasing education is likely to lead to health benefits (Mauro, etal 2014 \&Tillmann, etal 2018). 
Knowledge and technological advancement give rise to further challenges for nurses caring for these patients. Benefit in terms of knowledge and practice acquisition, enhanced self-care, reduced anxiety, increased satisfaction with care, improved pain control, and a reduced disruption in daily functioning. Finally, Patient education guidelines and programs attract patients to the provider and increase their satisfaction with their care. (Koren \& Sharaf, 2016 \& Parker \& Joanne, 2017).

The role of the professional nurse in the care of the patient undergoing cardiac catheterization is beneficial for obtaining a positive outcome for the patients throughout an era of increasing competition in health care (Mohammed, etal \& Marcus, 2014). Because of the increasing numbers of outpatient heart catheterizations, nurses play a pivotal role in patient assessment, safety, support, and education. To deliver optimal care, nurses need to prepare the patient adequately both physically and emotionally. Adequate assessment and monitoring throughout the pre catheterization, intra catheterization, and post catheterization experience are paramount in avoiding complications and ensuring successful outcomes (Moser, \& Riegel, 2012).

People who were provided educational guidelines subsequently developed less coronary heart disease. Increasing the number of years that people spend in the educational system may lower their risk of subsequently developing coronary heart disease by a substantial degree. These findings should stimulate policy discussions about increasing educational attainment in the general population to improve population health. (Bēta, 2014; Parker \& Joanne, 2017).

A patient must be adequately prepared intellectually and practically to manage their disease, instructions from their physician, most important practices needed and potential complications of any interventions as the more clearly a disease is understood, the more likely it is that an individual will be comfortable with their care. (Bêta, 2014 \& Tillmann, etal 2018).

Hence, Patients' undergoing $\mathrm{CC}$, can be extremely intimidating. Adequate knowledge about what can be expected pre, during and after the procedure is critical. So nurse should provide the CC patients all knowledge about CC procedure and practices needed as breathing exercise, feet exercise and back massage and oral medication 
practice as it is the most method of drug administration used for them and also prevention of cardiac attacks. And this is the aim of the present study.

\section{AIM OF THE STUDY}

The aim of the present study was to determine the level of knowledge and practice of patients undergoing cardiac catheterization in Suez Canal University Hospitals in Ismailia.

To fulfill the aim of the study, the following research question was formulated: Are the patients undergoing CC have satisfactory level of knowledge and practice?

The study was portrayed under the four main designs as follows:
A- Technical design.
B- Operational design.
C- Administrative design.
D- Statistical design.

\section{SUBJECT AND METHOD}

Research design: A descriptive research design was used in this study which was utilized to investigate the research question.

Setting: The study was carried out in the Cardiac catheterization Unit in the Suez Canal University Hospitals in Ismailia.

Subjects: The sample included100 adult male and female patients undergoing cardiac catheterization in the Cardiac catheterization Units of Suez Canal University Hospitals with different educational and experience level who are willing to participate in the study. Patients were selected from the daily list in the cardiac catheterization unit during the period of data collection and were included in the study after obtaining their informed consent.

\section{Tools for data collection:}

\section{Tool I:}

\section{Patients' Interview questionnaire:}

This tool was prepared by the researcher, and it was written in Arabic language and composed of three parts: 
Part 1:It was used to assess patients' demographic characteristics: It included the patients' age, sex, residence, level of education and occupation.

Part 2: This part was used to collect patients' related medical data: it included date and time of admission, no. of previous CC, type of current CC, smoking, associated medical diseases and allergies. Also it include weight in $\mathrm{kg}$ and height in centimeter then body mass index (BMI) was calculated according to the law; weight in relation to height, calculated mathematically by dividing weight in kilograms by the square of height in meters (National Center for Health Statistics 2011; Mohammed, 2014 \& Douglas, etal 2015 )

Part 3: This part was concerned with patients' knowledge assessment: It was prepared by the researchers based on relevant literature review (Douglas, etal 2013; WHO, and Amin, 2015 \& Hardin \& Kaplow 2016) and it was in the form of multiple choice questions (MCQ) and true and false questions.

One grade was given when the answer was correct and zero was given when the answer was incorrect. It was considered that Total knowledge scoring system were 44 grade and it was considered that $\geq 75 \%$ was satisfactory level of knowledge ( $\geq 33$ grade ) but $<75 \%$ was un satisfactory level of knowledge ( $<33$ grade).

\section{Tool II:}

Patient's practice observational checklists tool: It was adapted by the researchers based on relevant literature review Abdelmonem, (2010), W. H. O (2015), Kerry, (2014), Lynda, (2014) and Hardin \& Kaplow, (2016), and included two parts: Part I: for self-management practices for pain management including, Breathing exercise, Feet Exercises, Back message and Oral administering medications

One grade was given when the answer was correct and zero was given when the answer was incorrect. So the total score was 66 grades and it was considered that $\geq 75 \%$ was satisfactory level of practice ( $\geq 49.5$ grades ) but $<75 \%$ was un satisfactory level of practice $(<49.5$ grades $)$. 


\section{A) Operational design:}

The operational design includes preparatory phase, tools validity, reliability, pilot study and field work.

Preparatory phase: It includes reviewing of recent literature, different studies and theoretical knowledge of various aspects of the research topic using books, articles, internet, periodicals and magazines.

Tools validity: Content validity (or logical validity) was performed to measure the extent to which the tools represent all facets of the social psychometrics construction. The method of measuring content validity was performed by gauging agreement among raters/judges regarding how essential of a particular item of the tools is.

The developed tools were submitted to 7 experts in the field of cardiology, and medical surgical nursing for content validity and the necessary modifications were done.

Reliability:Coefficient of reliability of the developed tools for knowledge and practice was measured by Cronbach's $\alpha$ alpha. The reliability scores of the previous tools as above were (0.866 and 0.901$)$ consequently, which indicate high tool internal consistency of the used tools.

Pilot study:A pilot study was carried out on $10 \%$ of the study sample to check and ensure clarity, applicability, and feasibility of the tools and to identify the difficulties that may be faced during the application. Suggested changes were done then it was put into its final form, and they were not included in the study sample.

\section{Field work:}

Data was collected from the selected setting by the researcher using the preconstructed tools. Through the Assessment phase. As initial assessment for the level of knowledge and practice of every patient was done on admission using Tool 1 and Tool II (An interview questionnaire sheet) pre Cardiac catheterization procedure and pre educational guidelines. 


\section{B) Administrative design:}

An official permission was obtained using proper channels of communication. Official letters were sent from the Faculty of Nursing, Suez Canal University to the director of each study setting, explaining the aim of the study and its expected outcome to take their permission to carry out the study. Acceptance of directors of Suez Canal University Hospitals in Ismailia was also obtained.

\section{C)Statistical design:}

Upon completion of data collection variable included in each data collection sheet were organized and tabulated then coded prior to computerized data entry. The data were then imported into Statistical Package for the Social Sciences (SPSS version 22) software for statistical analysis.

The quantitative data were presented as means and standard deviation (SD) and the qualitative data were presented as frequency and percentage. According to the type of data, the following tests were used to test differences for significance; Unpaired Student T-test was used to compare between related samples, Chi-square the hypothesis that the row and column variables are independent, without indicating strength or direction of the relationship. Pearson chi-square and likelihood-ratio chi-square. T-test and Yates' corrected chi-square are computed for $2 \times 2$ tables.

\section{RESULTS:}

\section{SECTION I: Demographic characteristics and medical history:}

The study showed that showed that, $74 \%$ of the patients included in the study were aged 50$>60$ years old. Concerning gender, $63 \%$ were males. Regarding to residence, $71 \%$ were of the urban population. In relation to educational level, only $11 \%$ had bachelor degree, finally $46 \%$ of them were occupying professional working and $38 \%$ of them weren't working.

Regarding to medical history $85 \%$ of the patients included in the study undergoing diagnostic CC. Regarding to smoking $20 \%$ were smokers and $35 \%$ were quitter. In relation to associated medical diseases, $48 \%$ were hypertensive and $32 \%$ of them were diabetic. Finally, $100 \%$ of them had no allergy and $66 \%$ of them were obese. 


\section{SECTION II: patients' knowledge:-}

\section{Part 1: Knowledge about anatomy and physiology of the heart:}

The minority of the studied patients had satisfactory level of knowledge regarding structure of the heart, type of blood in right side of the heart, coronary artery diseases, the origin of aortic artery in the heart, number of heart valves and causes of heart conduction system changing in $13 \%, 9 \%, 10 \%, 7 \%, 12 \%$ and $2 \%$ respectively.

Part 2: Knowledge about basics of cardiac catheterization including (purposes and types; preparation; complications of $\mathrm{CC}$ and post cardiac catheterization instructions)

The minority of the studied patients had satisfactory level of knowledge regarding basics of cardiac catheterization, also there were high statistically significant differences as $p$ value is $<0.001$.

\section{Part 3: Knowledge about prevention of cardiac attack:}

The results showed that $4 \%$ of the studied patients had satisfactory level of knowledge about prevention of cardiac attack. With a high statistical significant difference as $\mathrm{p}$ value is < 0.001

\section{Part 4: Knowledge about discharge instructions:}

The results showed that, the minority of the studied patients had satisfactory level of knowledge regarding suitable time for taking bath, diet, driving, returning to work and reasons for seeking medical care in $15 \%, 10 \%, 8 \%$ and $7 \%$ respectively. Also there were high statistically significant differences as $\mathrm{p}$ value is $<0.001$.

Figure (1): showed that $1 \%$ of the studied patients had satisfactory level of total knowledge. With a high statistical significant difference as $\mathrm{p}$ value is $<0.001$.

Figure (2): showed that that showed that none of the studied patients had satisfactory level of breathing exercise practice. With a high statistical significant difference practice as $p$ value is $<0.001$ 
Figure (3): showed that $4 \%$ of the studied patients had satisfactory level of feet exercise practice. With a high statistical significant difference as $\mathrm{p}$ value is $<0.001$

Figure (4): Showed that $9 \%$ of the studied patients had satisfactory level of back massage exercise practice. With a high statistical significant difference as $\mathrm{p}$ value is $<0.001$

Figure (5): showed that $10 \%$ of the studied patients had satisfactory level of oral medication administration practice. With a high statistical significant difference as $\mathrm{p}$ value is $<0.001$.

Table (1): percentage distribution of demographic data of the studied patients undergoing cardiac catheterization $(\mathrm{N}=100)$.

\begin{tabular}{|c|c|c|}
\hline Demographic data & $\mathbf{N}$ & $\%$ \\
\hline \multicolumn{3}{|l|}{ Age } \\
\hline$<50$ & 26 & 26.0 \\
\hline $50-60$ & 34 & 34.0 \\
\hline$>60$ & 40 & 40.0 \\
\hline Range & \multicolumn{2}{|c|}{$30-79$} \\
\hline Mean \pm SD & \multicolumn{2}{|c|}{$56.08 \pm 9.704$} \\
\hline \multicolumn{3}{|l|}{ Sex } \\
\hline male & 63 & 63.0 \\
\hline female & 37 & 37.0 \\
\hline \multicolumn{3}{|l|}{ Residence } \\
\hline Urban & 71 & 71.0 \\
\hline Rural & 29 & 29.0 \\
\hline \multicolumn{3}{|l|}{ Level of education } \\
\hline Illiterate & 18 & 18.0 \\
\hline Read and write & 11 & 11.0 \\
\hline Basic education & 27 & 27.0 \\
\hline Secondary education & 33 & 33.0 \\
\hline Bachelor degree & 11 & 11.0 \\
\hline \multicolumn{3}{|l|}{ Occupation } \\
\hline Not working & 38 & 38.0 \\
\hline Manual & 16 & 16.0 \\
\hline Professional & 46 & 46.0 \\
\hline
\end{tabular}




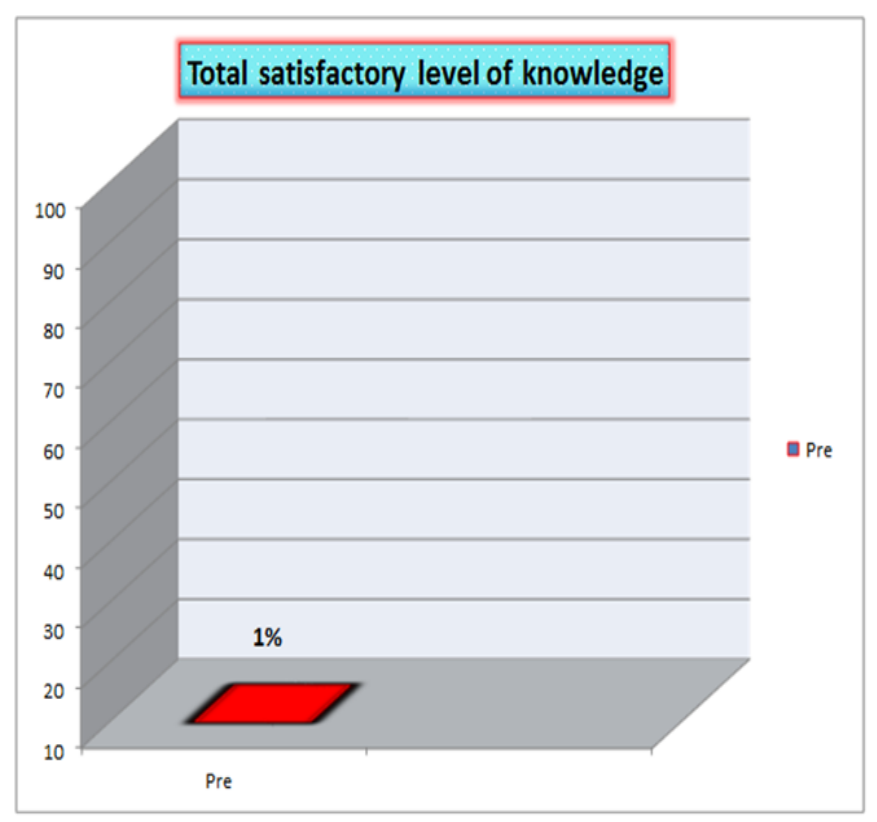

Figure (1) percentage distribution of patients' total satisfactory level of knowledge:

Section III: patients' undergoing cardiac catheterization practices about self-care and pain management:

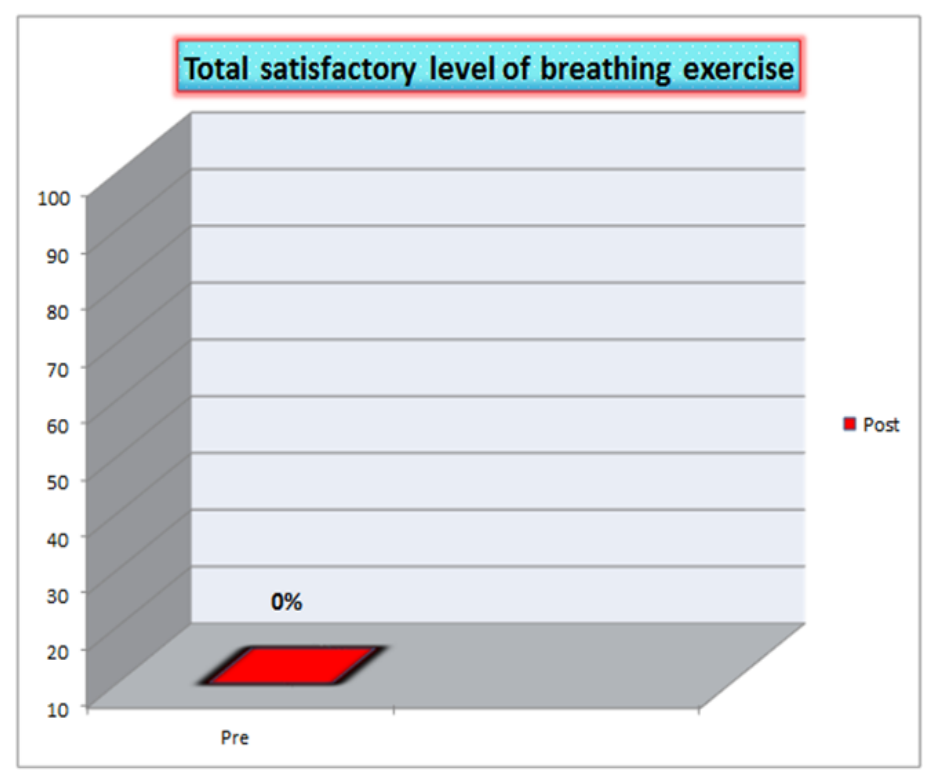

Part 1: Figure (2) patients' total satisfactory level of breathing exercise practice 


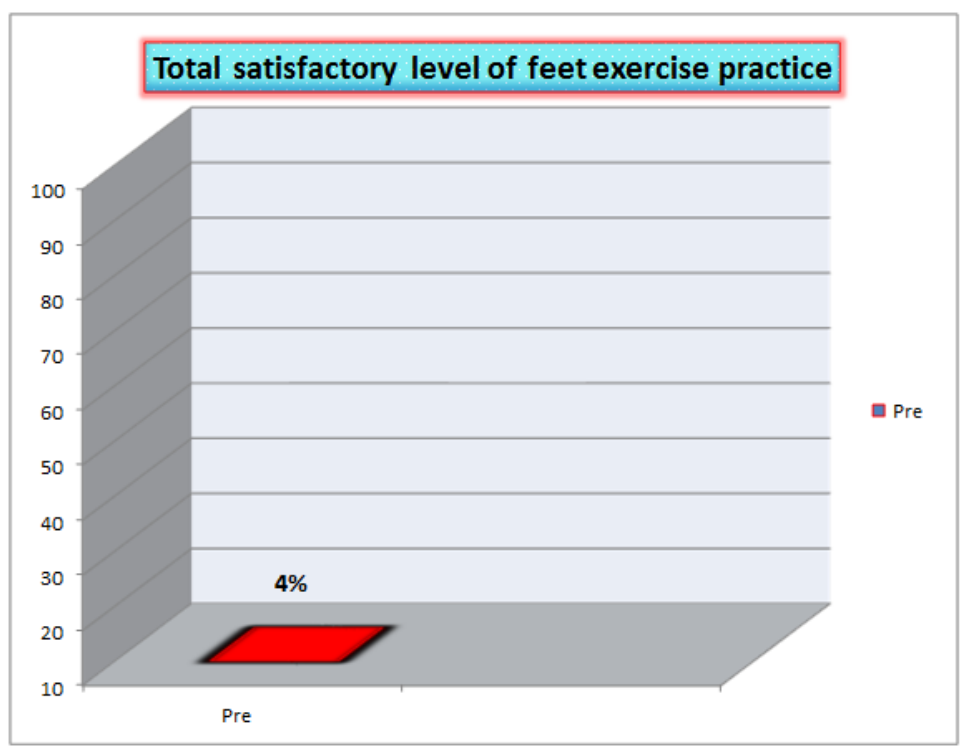

Part 2: Figure (3) percentage distribution of patients' total satisfactory level of feet exercise practice $(N=100)$

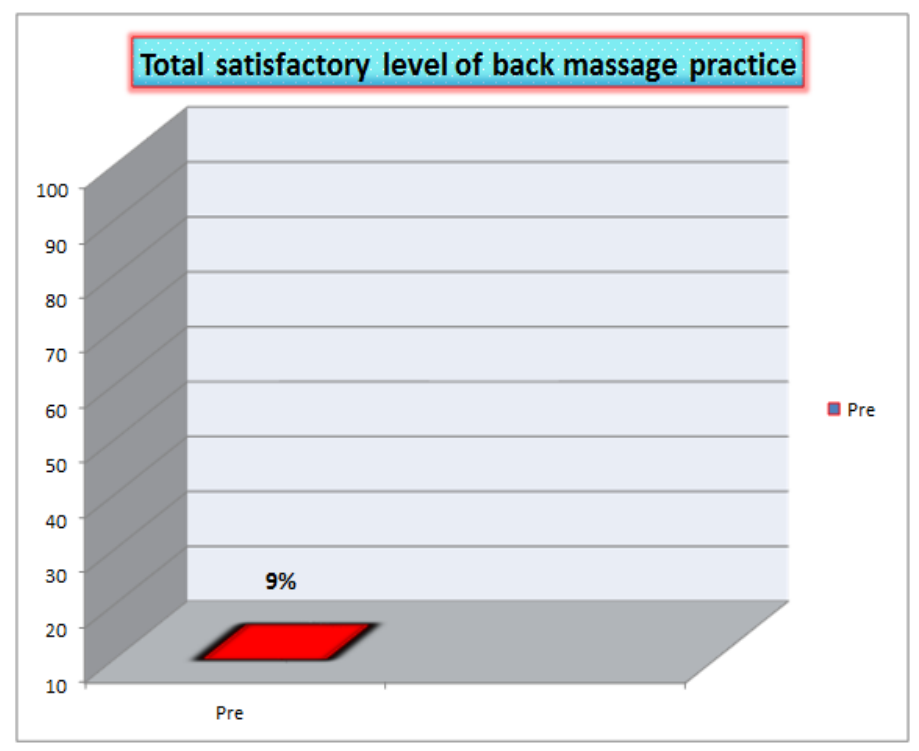

Part 3: Figure (4) percentage distribution of patients' practice about back message $(N=$ 100)

Figure (5) percentage distribution of patients' satisfactory level of oral medication administration practice $(N=100)$ 


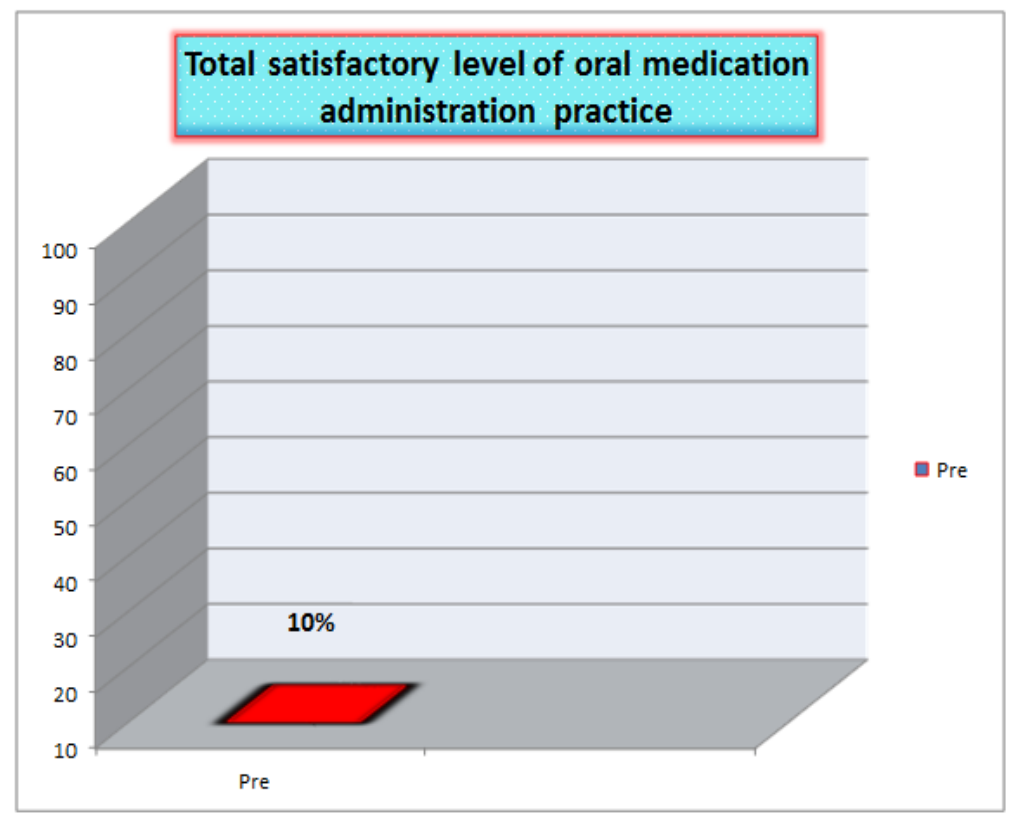

Part 4: Figure (5) percentage distribution of patients' satisfactory level of oral medication administration practice $(N=100)$

\section{DISCUSSION:}

Coronary artery diseases touch the lives of millions of patients and their families, together with those who provide and plan care, and those responsible for planning and funding care especially in developing countries like Egypt. Indeed, the WHO estimates that $60 \%$ of the global burden of CAD occurs in developing countries (Beltrame, etal 2012; Kern, 2016 \& Tillmann, etal 2018). Cardiac catheterization (CC) is the most definitive procedure in the diagnosis, therapeutic (PCI) and evaluation of CAD, and currently it has become the routine diagnostic procedure performed in many hospitals. Femoral artery is commonly used in daily cardiology practice because of its larger diameter. (Chair, etal 2012\& Tillmann 2018).

Patient educational process relevant to the patient's level of understanding, comprehensive, delivered at the appropriate time, as well as designed to understand can be one of the prerequisites for the patient to get some inspiration to change attitudes, increase knowledge, practice, motivation and awareness of the importance of co-responsibility to 
make decisions about medical treatment, the patient's behavior or change of habits. (Bēta, 2014 \&) Koren \& Sharaf, 2016).

Nurses play a critical pivotal role in delivering care through patient assessment, safety, support and education. To deliver optimal care, nurses need to prepare the patient adequately both physically and emotionally. Adequate assessment and monitoring throughout the precatheterization, intracatheterization, and postcatheterization experience are paramount in avoiding complications and ensuring successful outcomes (Mohammed, 2014 \& Amin, 2015).

The aim of the present study was to determine the level of Knowledge and Practice of Patients Undergoing Cardiac Catheterization.

The study included 100 adult patients undergoing $\mathrm{CC}$ with different educational and experience level who are willing to participate in the study. A convenient sample of patients were selected from the daily list in the cardiac catheterization unit during the period of data collection and were included in the study after obtaining their informed consent. And it was conducted in the Cardiac Catheterization care unit, affiliated to Suez Canal University Hospitals in Ismailia.

To fulfill the aim of this study, the following research question was formulated: Are the patients undergoing CC have satisfactory level of knowledge and practice?

Interpretation and discussion of results obtained from the current study were presented in three main sections; the first section described the patients' demographic data and medical history of the study subjects. The second section was concerned with patients' level of knowledge. The third section was concerned with patients' practice.

\section{Section 1: socio-demographic characteristics}

In our study, According to the age, more than two thirds of the patients included in the study were aged 50->60 years old. The result of the present study is supported by Mohammed (2014) who stated in her study that $56.0 \%$ and $52.0 \%$ respectively of both study and control group patients were in the age between (50-65 years) with mean age of both study and control groups were approximately equal of (53.88 years) and (52.2 years) .The result of the present study is supported by Williams, etal (2018) where mean age of cardiac 
catheterization cases was 58 years old. Also this supported by Bagnall, etal (2009) who stated that rates of in-hospital catheterization and revascularization increased over time ( $\mathrm{p}$ $<0.001)$, the largest increase occurred in patients aged $<65$ years.

On the other hand Chair, etal (2012) stated that the average age the participants on his study was 63 years old. Moreover, the result of present study is far away from results of Abdeaal, etal (2013) who found the mean age of PCI patients was 62 years.

This mean age of the present study may be due to aging which is an un-modifiable risk factor for CAD. The WHO reports that the principal cause of death of people over 65 years is $\mathrm{CAD}$, and CAD risk increase as age increases. In many develop countries, the number and proportion of older people (i.e. over 65 years) is increasing Kucia, \& Quinn, (2010), Beltrame, et al (2012), Fuster, \& Kelly, (2010).

Regarding gender, the present study clarified that about two thirds of the study group were males. This finding is in line with Mohammed (2014) who found that more than half of both the study and control group patient were males. Also the result of the present study is supported by Abdeaal, etal (2013) \& Amin (2015) who indicates that $64 \%$ of PCI cases were men. On the other hand, this result may be not in line with Beltrame, etal (2012) who reported that $\mathrm{CAD}$ is the leading cause of mortality for both adult males and females alike worldwide. Although the initial manifestation of CAD is delayed in females by about ten years compared to males, there is no abrupt increase in CAD mortality rates for females immediately following menopause but a progressive increase over subsequent years.

Regarding residence, the result revealed that more than two thirds of patients participating in the study were of the urban population. The present study is supported by Sekhri (2014) who conclude that his study demonstrated a high prevalence of CAD risk factors in the Indian urban population. Also the result of the present study is supported by Amin (2015) who concluded that more than three quadrant of her study patients were from urban population.

This result may ascertain that belonging to urban population may limit the time for traditional cooking and they may turn to prepared and foods that are often high in sugar, salts, saturated and trans-fats, which in turn increase the risk of CAD. Besides, restricted 
time rise rates of transport by car rather than transport by foot, discourage physical activity and encourage sedentary habits. Moreover.

Regarding education and occupation the present study revealed that the minority of study population had bachelor degree. The result of the present study is supported by Tillmann, etal (2018) who concluded that low education is a causal risk factor in the development of coronary heart disease. On the other hand the present study was not on same line with Mohammed (2014) who stated that $44.0 \%$ of her study patients were university education certificate. Also the result of present study is supported by Chair, etal (2012) who mentioned that $62.8 \%$ of the participants in his study received no education or were educated at a primary school level. This result may ascertain that decreasing educational level may be a cause of the unsatisfactory level of knowledge of the patients. And increasing educational level should increase satisfactory level of knowledge.

Regarding occupation, the result of the present study revealed that $46 \%$ of the study patients were occupying professional works. This result is supported by Rosch \& Marksberry (2017) who mentioned in his study about Stress and Heart Disease that the relationship between job stress and cardiovascular disease was scientifically demonstrated 15 years ago also, there are certain occupations are extremely stressful and therefore more likely to cause heart disease. So the relationship between stress, heart disease and sudden death has been shown to increase significantly as a consequence of any severe stressor that evokes "fight or flight' responses.

On the other hand, this result is not on the line with Biglari, etal (2016) who mentioned that his study results did not suggest a considerable relationship between risk factors of cardiovascular diseases and occupational stress among intercity drivers. This result may ascertain that occupying professional works limit the time for traditional cooking and they may turn to prepared foods that are often high in sugar, salts, saturated and transfats. Gaining calories from sugar and fats has become cheaper and more accessible than fruits, vegetables and grains that in turn increase the rates of diabetes mellitus, hypertension and hyperlipidemia and this increase the risk of CAD.

Concerning the type of $\mathrm{CC}$, the result of the present study revealed that the majority of the patients included in the study undergoing diagnostic $\mathrm{CC}$. The result of the study ascertained by Lee, etal (2017) who concluded that the high PCI consumables cost 
highlighted the importance of cost-effective purchasing mechanism. Findings on the heterogeneity of the patients, treatment practice and hospitalization cost are vital for formulation of cost-saving strategies to ensure sustainable and equitable cardiac service.

Also Ong, etal (2017) who concluded that providing valuable guidance for service planning. Alternative procurement practices for PCI consumables may deliver cost reduction. For countries with limited data availability, costing method tailored based on country setting can be used for the purpose of economic evaluations. This may be due to two reasons toward the present result, first, medically a sum of patients suspected to have coronary artery disease and referred for angiography turned on to have normal coronaries and alternate diagnosis is sought. Second financial aspect as the patient can afford to pay for diagnostic angiography either by himself or by insurance but when there is PCI using 1 or more stent he needs to pay much more money which he cannot afford.

Concerning smoking, the result revealed that more than half of all patients had a history of smoking. The result of the present study is supported by Mohammed (2014); Amin (2015); Byrne \& Espnes (2016) \& Rosch \& Dimsdale (2017), who mentioned that Cigarette smoking pose an established and potent risk for CVD who studied "The effect of changing position and early ambulation after cardiac catheterization". Also, Law \& Wald (2013) who studied "Environmental tobacco smoke and ischemic heart disease" and evidenced the presence of a significant effect of tobacco smoke exposure in causing ischemic heart disease. This result ascertains that smoking is a modifiable risk factor of CAD.

Concerning to associated medical diseases, the result of the present study revealed that about half of patients were hypertensive and about one third of them were diabetic. The result of the present study is supported by Mohammed (2014) \& Amin (2015) who studied "The effect of implementing a clinical pathway on health outcomes of patients undergoing percutaneous coronary intervention (PCI)" and mentioned that 52\% of her study groups were suffering from hypertension and $48 \%$ had diabetes mellitus. Also, American Heart Association (AHA) (2017) which reported a positive association between hypertension and insulin resistance as when patients have both hypertension and diabetes, which is a common combination, their risk for cardiovascular disease doubles. This demonstrates the importance of prevention of hypertension and diabetes occurrence, and also demonstrates the beneficial of hypertension and diabetes control in secondary prevention of CAD. 
Concerning to obesity, the result of the present study revealed that more than two thirds of them were obese. This result harmonious with Jahangir, etal (2014) who studied " The relationship between obesity and coronary artery disease" and mentioned that there are major health implications associated with obesity, including diabetes mellitus, dyslipidemia and all independent risk factors for coronary artery disease(CAD). Also AHA (2016) which mentioned that Obesity is a major risk factor for cardiovascular disease. Also Smith, etal (2012) who concluded that obesity is associated with increased risk of cardiovascular disease (CVD) mortality. Correspondingly, Abdeaal, etal (2013) reported that 7\% of PCI patients had dyslipidemia.

\section{Section II: patients' level of knowledge}

Regarding to patients' level of knowledge about cardiovascular system and cardiac catheterization basics knowledge, the result of the present study revealed that the result of the present study revealed that most of the study group patients had unsatisfactory level knowledge pre guidelines intervention. The present result is in line with Parker \& Joanne (2017) who studied, "Relationship of Functional Health Literacy to Patients' Knowledge of Their Chronic Disease". And concluded that inadequate functional health literacy poses a major barrier to educating patients with chronic diseases.

Also Samira, etal (2016) who studied "Effect of Early Nursing Preparation on Anxiety among Patients Undergoing Cardiac Catheterization", Who used cardiac catheterization knowledge assessment sheet including definition of catheterization, causes, sites of catheter entry, purpose, patient preparation, number's fasting hours before the procedure, medication, investigation before the procedure, time of the procedure, position after the procedure, movement after the procedure, nutrition and post procedure complication. And concluded that the study group had better knowledge than control group as clarified that, the early preparation and providing patients' information before cardiac catheterization improved patients' knowledge.

On the other hand, Wilson, etal (2014) who studied, "Advancing effective communication, cultural competence, and patient- and family-centered care: A roadmap for hospitals". And concluded that, not all patient education was successful. In reality, communication was often partially understood, misunderstood, or misinterpreted. Even with 
the best of intentions, patient education that failed to educate can lead to adverse events or poor outcomes.

All these may ascertain that, the early preparation and providing patients' information before cardiac catheterization improve patients' knowledge and patients' outcomes.

Concerning to patients' level of knowledge about post cardiac catheterization instructions including self-care, nutrition, positions and ambulation after $\mathrm{CC}$, the result of the present study revealed the result of the present study revealed that most of the study group patients had unsatisfactory level knowledge pre guidelines intervention. The present result is in line with Samira, etal (2016) who gave knowledge and teaching about pre, post cardiac catheterization through reading the pamphlet (brochure information) including position after the procedure, number's fasting hours before the procedure, movement after the procedure and nutrition.

Also, Kaur, etal (2007) who found through his study that the preoperative teaching is an extremely effective media to increase the level of performance of the subjects as information about self-care activities for patients undergoing cardiac surgery.

Regarding to patients' level of knowledge about prevention of cardiac attack, the result of the present study revealed the result of the present study revealed that most of the study group patients had unsatisfactory level knowledge pre guidelines intervention. The present result is in line with Ferdinand \& Patterson. (2012) who studied "Community-Based Approaches to Prevention and Management of Hypertension and Cardiovascular Disease". And concluded that Investments in effective prevention strategies provided the best opportunity to improve the health of Americans and control health care spending. As multiple community programs have been successful, to varying degrees, in identifying and educating individuals at risk. And in his final analysis mentioned that community education and outreach supplemented standard therapy for hypertension and CVD risk.

On contrarily, the present results is not on line with Edworthy, etal (2007) who studied "Effects of an enhanced secondary prevention program for patients with heart disease". And concluded that the intervention program failed to improve outcomes in the 
study. One explanation for these results was the near optimal physician compliance with guidelines in both groups.

Regarding to patients' level of knowledge about discharge instructions, the result of the present study revealed the result of the present study revealed that most of the study group patients had unsatisfactory level knowledge pre guidelines intervention. The present result is in line with Mukherjee, etal (2017) who studied, "The impact of health literacy on cardiovascular disease". And concluded that there was evidence that improved knowledge of one's condition may improve patient adherence to lifestyle changes and medication. Also showed statistically significant correlations between patients' general knowledge about coronary heart disease (CHD) risk factors and improvements in weight loss, physical activity, stress management, dietary changes, and reaching treatment goals for lipid levels. Self-knowledge was also positively related to adherence with antihypertensive drugs.

Regarding to patients' level of total knowledge. The result of the present study revealed that most of the study group patients had unsatisfactory level knowledge pre guidelines intervention. The present result is in line with Nag \& Ghosh (2014) who mentioned that low and middle educational status urban subjects in India have greater cardiovascular risk. Uneducated and less educated people major coronary risk factors such as smoking and hypertension are more prevalent. This may make these people prone to coronary heart disease.

Also, the result of the present study is supported by Janati, etal (2011) who concluded that people from lower/middle social classes including low knowledge level were in greater CHD risk than higher social classes. Additionally Phillips (2010) who mentioned socio economic status (SES) including low knowledge level influences on CHD particularly those related to self-perception and social perception. For example, living and working in lower SES environments may contribute to diminished self-esteem, lower sense of control, and a reduced orientation toward mastery and efficacy. He mentioned also, individuals lower in SES experiencing higher rates of morbidity and mortality than higher-SES individuals. This relationship is particularly evident in the case of coronary heart disease (CHD). 


\section{Section III: patients' practice:}

Regarding to patients' level of practice about breathing exercise, the result of the present study revealed the result of the present study revealed that most of the study group patients had unsatisfactory level practice pre guidelines intervention. The result of the present study is supported by Alkan, etal (2017) who studied "Influence of Breathing Exercise Education Applied on Patients with Heart Failure on Dyspnea and Quality of Sleep". Breathing exercises were taught to patients in experiment group and they were told to make breathing exercises for 30minutes daily. Who indicated that exercise training programs demonstrate positive effects on exercise capacity, functional capacity, symptomatic status, quality-of-life and sleep quality in patients with cardiac failure.

In addition, Achttien, etal (2013) who studied "Exercise-based cardiac rehabilitation in patients with coronary heart disease": a practice guideline. And demonstrated that a relaxation program (including breathing therapy) is recommended in CHD patients. A relaxation program reduces cardiac mortality and morbidity, and has a favorable effect on physical, psychological and social parameters (including resting heart rate and fear of exercise).

Regarding to patients' level of practice about feet exercises, the result of the present study revealed the result of the present study revealed that most of the study group patients had unsatisfactory level practice pre guidelines intervention. The result of the present study is supported by Osondu (2016) who studied "Counseling Patient with Heart Failure" which aimed to describe how to educate patients on the health implications associated with heart failure and self- care management (including feet exercises). And to evaluate the effect of patient counseling on heart failure patient in regards to patient's quality of life, compliance (QOL). Who clarified that patient health standard and functional capacity was improved via patient counseling. Patient who participated in evidence base care programme which comprises of medication and counseling intervention show enhanced improvement in QOL.

In addition, Tanaka, etal (2016) who studied "The use of a novel in-bed active Leg Exercise Apparatus (LEX) for increasing venous blood flow after cardiac surgeries". Subjects performed two types of exercise; exercise 1 consisted of leg exercises using the LEX, while exercise 2 consisted of in-bed active plantar flexion/dorsiflexion exercises, results demonstrated that blood flow reached a maximum value 1 minute after exercise for 
both exercise types. This ascertain that patients' education about feet exercises practice had a positive effect on patient practice improvement as evidenced by improvement of patient outcomes.

Regarding to patients' level of practice about back massage exercise, the result of the present study revealed the result of the present study revealed that most of the study group patients had unsatisfactory level practice pre guidelines intervention. The result of the present study is supported by Kennedy, etal (2016) who studied "Process for massage therapy practice and essential assessment". It was clarified that the goal of providing these models was to give best practices for massage therapy treatment of low back pain and stress to deliver the best possible care. Also this ascertain that patients' education about feet exercises practice had a positive effect on patient practice improvement as evidenced by improvement of patient outcomes.

Moreover, Miozzo, etal (2016) whose study aimed to "review the effects of treatment with massage therapy on the symptoms of pain and anxiety reported by patients who underwent heart surgery". Through patients, who underwent heart surgery, comparing the postoperative treatment with massage and the usual treatment, it was demonstrated that Massage therapy might be a useful method to reduce pain and anxiety in patients undergoing cardiac surgery. And this ascertain that patients' education about back massage exercises practice had a positive effect on patient practice improvement as evidenced by improvement of patient outcomes.

Regarding to patients' level of practice about oral medication administration practice, the result of the present study revealed the result of the present study revealed the result of the present study revealed that majority of the study group patients had unsatisfactory level practice pre guidelines intervention. The result of the present study is supported by Victor \& William (2012) \& Peter (2017) who studied "A Structured Teaching and Self-management Program for Patients Receiving Oral Anticoagulation". And Hemostasis and Thrombosis: Basic Principles and Clinical Practice. Who concluded that an anticoagulation education program that includes self-management of anticoagulation therapy results in improved accuracy of anticoagulation control and in treatment-related quality-of-life measures.

Additionally, Murray, etal (2014) who studied "Training for patients in a randomized controlled trial of self-management of warfarin treatment". It was showed that 
self-management (including oral medication administration) can lead to improvements in patients' self-efficacy, closer adherence to treatment, and increased control of treatment with oral anticoagulants. This mean that patients' education about oral medication administration practice had a positive effect on patient practice improvement as evidenced by improvement of patient outcomes.

Regarding to patients' level of total practice. The result of the present study revealed that most of the study group patients had unsatisfactory level practice pre guidelines intervention. The result of the present study is supported by Erhardt (2018) who mentioned that for cardiovascular risk reduction, the implementation of knowledge into practice has been shown to be poor. Hence he concluded that Practice guidelines on the prevention of cardiovascular disease have been widely disseminated, but their implementation has been shown to be poor. Several reasons for this 'guidelines gap' have been identified. Physicians' and patients' perceptions of cardiovascular risk factors are highly deficient and physicians need a better understanding of the needs of their patients. Compliance programs should therefore be multidimensional, involving both the patients' and doctors' perspectives.

The result of the present study is also supported by Oli, etal (2014) who mentioned that earlier studies on health literacy and the behavior dimension of cardiovascular health reported a substantial gap between knowledge and practice. Hence he concluded that although better health care is important in terms of aiding patients to better understand and cope with their disease, interventions should be tailored to improve the community's cardiovascular health literacy and preventive practices.

\section{REFERENCES:}

Abdelaal, E., Rao, S., Glchrist, I., Bernat, I., Shroff, A., Caputo, R., Costerousse, O., Pancholy, S. and Bertrand, O. (2013): Same-day discharge compared with overnight hospitalization after 1 uncomplicated percutaneous coronary intervention: a systemic review and meta-analysis. J Am Coll Cardiol Intv ;6 (1): 99-112.

Abdelmonem, S. (2010): Effect of self- care Program on Quality of life for Myocardial Infarction Patients. Un published doctorate thesis, Sues Canal University. Pp.5965. 
Achttien, R. J., Staal, J. B., Van, S., Kemps, H. M., Koers, H., Jongert, M. W. \& Hendriks, E. J. (2013): Exercise-based cardiac rehabilitation in patients with coronary heart disease: a practice guideline, US National Library of Medicine National Institutes of Health PubMed Central Journal (PMC); 21(10): 429-438.

American Heart Association (2016): Obesity Information - American Heart Association.

http://www.heart.org/HEARTORG/HealthyLiving/WeightManagement/Obesity/ObesityInformation_UCM_307908_Article.jsp\#.Whkq6NKnHIU

Alkan, O., Uysal, H., Enç, N., and Yigit, Z. (2017): Influence of Breathing Exercise Education Applied on Patients with Heart Failure on Dyspnoea and Quality of Sleep: A Randomized Controlled Study, International Journal of Medical Research \&Health Sciences; 6(9): 107-113.

American Heart Association (2017): Cardiovascular Disease \& Diabetes. http://www.heart.org/HEARTORG/Conditions/More/Diabetes/WhyDiabetesMatters/Cardio vascular-Disease-Diabetes_UCM_313865_Article.jsp/\#.Whcq0tKnHIU

Amin, H. (2015): The effect of changing position and early ambulation after cardiac catheterization on patients' outcomes: Ismailia: faculty of nursing, Sues Canal University, un published Master thesis. pp. 8-97.

Bagnall, A., Goodman S., Fox, K. and Yan R. (2009): Influence of age on use of cardiac catheterization and associated outcomes in patients with non-ST-elevation acute coronary syndromes. The American journal of cardiology (Am J Cardiol.); 103(11):1530-6.

Beltrame, F., Dreyer, R. and Tavella, R. (2012): Epidemiology of Coronary Artery Disease, Coronary Artery Disease. Current Concepts in Epidemiology, Pathophysiology, Diagnostics and Treatment. Croatia: In Tech.

Bēta, G. (2014): Patient Education - Relevance in Nursing Education and Practice. Science and Education Publishing Journal; 2(7): 436-563.

Biglari. H, Ebrahimi, M. \& Salehi, M. (2016): Relationship between occupational stress and cardiovascular diseases. The International Journal of Occupational Medicine and Environmental Health; 29(6):895-901. 
Byrne \& Espnes (2016): Occupational Stress and Cardiovascular Disease. Wiley InterScience Journal; 24(3): 231-238.

Chair, Y., Yu, M., Choi, C., Wong, M., Sit, W. and Yim, W. (2012): Effect of early ambulation after transfemoral cardiac catheterization in Hong Kong: a single-blinded randomized controlled trial. The Anatolian Journal of Cardiology. By AVES Yayinilhk Ltd.; 12(3):222-30.

Douglas L., Peter, L. \& Robert O. (2015): Braunwald's Heart Disease: A Textbook of Cardiovascular Medicine, Percutaneous Coronary Intervention. $10^{\text {th }}$ Edition, by Saunders, an imprint of Elsevier Inc. pp. 1245-1262.

Edworthy, S., Bonnie, B., Donna, G., Rollin, F., Terry, C., Dante M., and Israel B., (2007): Effects of an enhanced secondary prevention program for patients with heart disease: A prospective randomized trial, The Canadian Journal of Cardiology ( Can J Cardiol) ; 23(13): 1066-1072.

Erhardt, L. (2018): Managing cardiovascular risk: reality vs. perception, Department of Cardiology, European Heart Journal Copyright (C) Oxford University Press; 7, (1): L11L15.

Ferdinand, C. \& Patterson, P. (2012): Community-Based Approaches to Prevention and Management of Hypertension and Cardiovascular Disease. Journal of Clinical Hypertension; 14(5):336-43.

Fuster, V. and Kelly, B. (2010): Promoting Cardiovascular Health in the Developing World: A Critical Challenge to Achieve Global Health. Institute of Medicine (US) committee on preventing the Global Epidemic of Cardiovascular Disease. Washington (DC): National Academies Press (US).

Hardin, S. \& Kaplow, R. (2016): Textbook of Cardiac Surgery Essentials for Critical Care Nursing 2nd Edition. By Jones \& Bartlett Learning books. ; PP. 13-247.

Jahangir, E., Schutter, A . \& Lavie, C. (2014): The relationship between obesity and coronary artery disease. U.S. National Library of Medicine, PubMed central medicine Journal; 164(4):336-44. 
Janati, A., Matlabi, H., Hamid, A. \&Leila, A. (2011): Socioeconomic Status and Coronary Heart Disease. U.S. National Library of Medicine, PubMed central medicine Journal; 1(2): 105-110.

Kaur, N., Verma, P. \& Singh, R. (2007): Effectiveness of planned preoperative teaching on self-care activities for patients undergoing cardiac surgery. PubMed central medicine, The Nursing Journal of India.; 98(6):131-2.

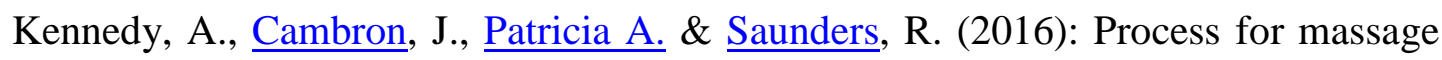
therapy practice and essential assessment. Journal of Bodywork and Movement Therapies, Elsevier; 20, (3), 484-496

Kern, J. (2016): The Cardiac Catheterization Handbook. 6th ed. Philadelphia: Saunders, Elsevier. Pp. 5-157

Kerry, (2014): Textbook of medical surgical nursing, cardio vascular system, edition 13, welters Kluwer, Lippincott Williams \& Wilkins, Philadelphia, London. Pp. 450-467

Koren, D. \& Sharaf, F. (2016): Impact of health education on compliance among patients of chronic diseases in Al Qassim, Saudi Arabia, International Journal of Health Sciences ;4(2): 139-148.

Kucia, A \& Quinn, T. (2010): Acute Cardiac Care: A practical Guide for Nurses. Oxford: Blackwell.

Law, M. \& Wald, N. (2013): Environmental tobacco smoke and ischemic heart disease. U.S National Library of Medicine. PubMed Journal; 46(1):31-8.

Lee, K., Ahmad, W., Low, E., Liau, S \&Hamzah, S. (2017): Comparison of the treatment practice and hospitalization cost of percutaneous coronary intervention between a teaching hospital and a general hospital in Malaysia: A cross sectional study; 12 (9), 11-114.

Lynda, J. (2014): Nursing care plans: Transitional patient \& family central care, coronary artery bypass grafting. 6th edition, Walters Kluwer, Lippincott Williams \& Wilkins, Philadelphia, London. Pp.509-570.

Marksberry, K. (2018): Stress and Heart Disease. The American Heart Association (AHA) available on: 
http://www.heart.org/HEARTORG/HealthyLiving/StressManagement/HowDoesStressAffec $\underline{\text { tYou/Stress-and-Heart-Health_UCM_437370_Article.jsp\#.Wm2QObynHIU }}$

Mauro, M. (2014): A Textbook of Grossman \& Baim's Cardiac Catheterization, Angiography, and Intervention $8^{\text {th }}$ Edition, by Lippincott Williams \& Wilkins, Walters Kluwer, Philadelphia. Pp. 1-39.

Minino, A., Murphy, S. and Kochanek,K.( 2012.) Deaths: Final data for 2008. National Vital Statistics Reports. Hyattsville: National Center for Health Statistics, Vol. 59 (10).

Miozzo, A., Camila, C. \& Bozzetto, B. (2016): Massage therapy reduces pain and anxiety after cardiac surgery: A systematic review and meta-analysis of randomized clinical trials. Elsevier B.V. Journal; 23(24): 1-16.

Mohammady, M., Heidari, K., Sari, A. A., Zolfaghari, M. and Janani, L. (2013): Early ambulation after diagnostic transfemoral catheterization. International Journal of Nursing Studies; 51 (1): 39-50.

Mohammed, G., Mohammed, Z., \& Al-Araby, H. (2016): Impact Of Designed Nursing Educational Protocol On Health Promotion For Patients Undergoing Coronary Artery Stent Outcome. IOSR Journal of Nursing and Health Science; 5 (2): 54-63.

Mohammed, H. (2014): The effect of implementing a clinical pathway on health outcomes of patients undergoing percutaneous coronary intervention (PCI): Alexandria: faculty of nursing, Alexandrea university.

Moser, D. and Riegel, B. (2012): Textbook of Cardiac Nursing: A companion to Braunwald's Heart Disease, $4^{\text {st }}$ edition, Saunders/Elsevier, Canada; PP. 239-248.

Mukherjee, D., Bates, E. \& Roffi, M. (2017): Cardiovascular Catheterization and Intervention: A Textbook of Coronary, Peripheral, and Structural Heart Disease, Second Edition. CRC Press, .Taylor \&Francis Group, Boca Raton. Pp. 253-274.

Murray, E., Fitzmaurice, D., \& Fuller, C. (2014): Training for patients in a randomized controlled trial of self-management of warfarin treatment, British Medical Journal (BMJ); 3 (1): 9-438. 
Nag, N. \& Ghosh, A. (2014): Cardiovascular disease risk factors in Asian Indian population: A systematic review, U.S. National Library of Medicine Elsevier Journal of Cardiovascular Disease Researche, 4(4): 222-228.

National Center for Health Statistics (2011): U.S. Department of Health and Human Services, Centers for Disease Control and Prevention Health, United States. New Yourk: DHHS,

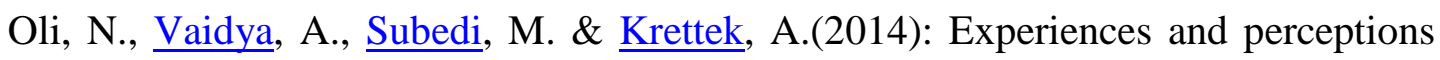
about cause and prevention of cardiovascular disease among people with cardio metabolic conditions: findings of in-depth interviews from a peri-urban Nepalese community. Global Health Action. Taylor \& Francis Group PubMed Journal; 7 (1): 10.3402.

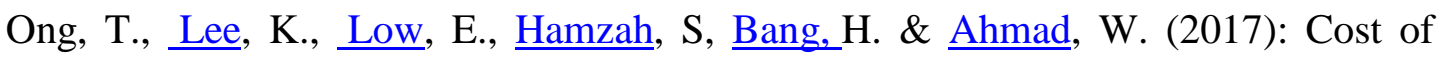
elective percutaneous coronary intervention in Malaysia: a multicenter cross-sectional costing study. PubMed, British Medical Journal (BMJ); 7(5): 430-437.

Osondu, M. (2016): Counseling Patients with Heart Failure Systematic Literature Review, Bachelor's Thesis, Seinäjoen ammattikorkeakoulu (SeAMK), Seinäjoki University of Applied Sciences. pp. 1-48.

Parker, V. \& Joanne, R. (2017): Relationship of Functional Health Literacy to Patients' Knowledge of Their Chronic Disease, Jama Internal Medicine Journal, Archive Internal Medicine, American Medical Association.; 158(2):166-172.

Peter T. (2017): A Structured Teaching and Self-management Program for Patients Receiving Oral Anticoagulation A Randomized Controlled Trial 281(2):145-150. American Medical Association.

Phillips, J. (2010): Socioeconomic Status and Coronary Heart Disease Risk: The Role of Social Cognitive Factor, PubMed Central (PMC) journal; 4(9): 704-727.

Rashad E. (2011): The Effect of the application of clinical pathway on postoperative outcomes of patients undergoing percutaneous nephrolithotomy. Alexandria: Unpublished DSN dissertation, Faculty of Nursing, Alexandria University. 
Rosch, P. \& Dimsdale, J. (2017): Stress More Important Than Ldl , The American Institute of Stress (AIS) Magazine, Psychological Stress and Cardiovascular Disease. Journal of the American College of Cardiology; 51(13): 1237-1246.

Samira, E., Nahid, F. \& Smah, E. (2016): Effect of Early Nursing Preparation on Anxiety among Patients Undergoing Cardiac Catheterization. American Journal of Nursing Science ; 5(5): 222-231.

Sekhri, T. (2014): Prevalence of risk factors for coronary artery disease in an urban Indian population. Peer-reviewed medical journal. (BMJ) Publishing Group; 4 (12): 1-8.

Tanaka, K., Kamada, H., \& Shimizu, Y. (2016): The use of a novel in-bed active Leg Exercise Apparatus (LEX) for increasing venous blood flow after cardiac surgeries. Published online article. Journal of Rural Medicine. 11(1): 11-16.

Tillmann, T., Vaucher, J. \& Okbay, A. (2018): Article, Education and coronary heart disease: mendelian randomization study. British Medical Journal (BMJ Publishing Group); 358:j3542.

Victor, J. \& William, C. (2012): Hemostasis and Thrombosis: Basic Principles and Clinical Practice. $6^{\text {th }}$ edition. Lippincott Williams \& Wilkins, pp. 1592.

Wells, J. \& Möller, A. (2015): Why do men suffer more heart problems than women? Gender differences in cardiovascular disease and comorbid depression. $\underline{\text { US }}$ National Library of Medicine National Institutes of Health, PubMed Central Journal (PMC). 9(1): 71-83.

Williams, D., Holubkov, R.,Yeh, W., Bourassa, M., Block,P., Coady, P., Cohen,H., Cowely, M. and Dorros G. (2018): Pecutaneous Coronary Intervention in the current Era Compared With 1985-1986 : The National Heart, Lung, and Blood Institute Registries. Circulation. American Heart Association Journal. Vol. 102, pp. 2945-2951.

Wilson, A., Paul, S. \& Christina L .(2014): Advancing effective communication, cultural competence, and patient- and family-centered care. Published by The Joint Commission International Agency (JCI); 102(1) 9:74. Available on: https://www.jointcommission.org/assets/1/6/ARoadmapforHospitalsfinalversion727.pdf. 
